\title{
Frequency Transformation to Design Single Band Circular Patch MMW Antennas
}

\author{
Mayar Elsebai* and Fawzy Ibrahim ${ }^{\dagger}$
}

\begin{abstract}
This paper introduces novel derived transformation equations to design single band circular antennas for Millimeter Wave (MMW) applications. The design utilizes the approach adopted for MMW antenna design based on an integrated Dielectric Resonator Antenna (DRA) in a Si-based technology platform for $77 \mathrm{GHz}$ MMW applications. The obtained optimized antenna by DRA is used as a reference and the proposed transformation is applied to calculate the new antenna design parameters that satisfy its given specifications without changing the geometry. Four Antennas are demonstrated by using this transformation. The desired frequencies are: 35, 60, 94 and $120 \mathrm{GHz}$; all lie in the MMW band to be utilized in several applications.
\end{abstract}

Keywords: Millimeter Wave Antenna or Frequency Transformation.

\section{Introduction}

EHF or Extremely High Frequency [1] and [2] is a band of radio frequencies in the electromagnetic spectrum designated by the International Telecommunications Union (ITU) range from 30 to $300 \mathrm{GHz}$; also known as Millimeter Wave (MMW) or band due to the range of wavelengths from 10 down to 1 millimeter.

The most utilized frequencies in the MMW are: 35, 60, 77, 94 and $120 \mathrm{GHz}$. The radiating frequency $35 \mathrm{GHz}$ [3] lies in the Ka band which is a band of frequencies ranges from 26.5 to $40 \mathrm{GHz}$ can be utilized in many applications; for example, we can use this frequency band in targeting radars on military aircraft with high resolution and close range and satellite communications.

The frequency that radiates at $60 \mathrm{GHz}$ is a part of an unlicensed frequency band that is commonly used for remote sensing applications and astronomy [3], satellites close to $60 \mathrm{GHz}$ utilizes remote sensors to determine the temperature in the upper atmosphere; this process is accomplished by measuring radiations emitted from the molecules of the oxygen that is a function of temperature and pressure. In addition to the previous applications, the $60 \mathrm{GHz}$ can be used to observe the atmosphere in case of climate and meteorological sensing applications. In the meanwhile, the U.S satellite sensors; for example, the Advanced Microwave Sounding Unit (AMSU) on NASA satellite and department of defense satellite in F-16 uses the $60 \mathrm{GHz}$ frequency as the operating frequency. Recently, the new technology approach targets the operating frequency to be near $60 \mathrm{GHz}$ in order to provide high signal directivity (pencil-beam like) that allows distinct systems to operate close to each other without subjecting to

\footnotetext{
* Teaching Assistant in ECE Department, Faculty of Engineering, Misr International University.

$\dagger$ Vice Dean of Faculty of Engineering, Misr International University.
} 
interference; one of the applications that will embrace this technology is the radar system with high resolution [4]. The upcoming WiFi standard, known as IEEE 802.11ad will operate at the $60 \mathrm{GHz}$ frequency with high data transfer up to $7 \mathrm{Gbps}$.

The most commonly used frequency band in the industrial bands for many applications is the $77 \mathrm{GHz}$ frequency which is part of the $\mathrm{W}$ band that ranges from 75 to $110 \mathrm{GHz}$. For radar sensors applications [5] and [6], the $77 \mathrm{GHz}$ frequency can be utilized; for example, the FMCW Radar Sensor that is designed by SIVERS IMA [4]. This sensor is used for speed measuring, position and distances for both security and surveillance purposes. In addition to all the previously mentioned applications, it can be used in the design of a radar system to direct an automotive cruise [7]. Automotive $77 \mathrm{GHz}$ radar systems have a very promising future; it permits high accuracy, precision and great scalability from short to long range; this new feature enables the future functions for helping the driver of the car and securing issues in the New Car Assessment Programs (NCAP) [8].

Another very commonly used frequency in the $\mathrm{W}$ band that is widely used in many applications is the $94 \mathrm{GHz}$ frequency [9]. A millimeter wave camera for detection of hidden weapons functions at $94 \mathrm{GHz}$. Also in astronomy applications, the use of $94 \mathrm{GHz}$ frequency in millimeter wave radar imaging applications with security and defense applications. In military applications, there is a less-than-lethal weaponry technology that uses the millimeter waves to make the temperature of a thin layer of the human skin high up to $54^{\circ} \mathrm{C}$ at a depth of $0.4 \mathrm{~nm}$ to pressurize the targeted person to move away; this is done by ejecting bursts last for two second of the $94 \mathrm{GHz}$ focused beam.

As for the $120 \mathrm{GHz}$ frequency; developing in optical communication technology has been taken into consideration for many years [10], the main idea is the conversion of the optical sub carrier signals along with data generated by photonic technology to electrical signals and radio waves by using Uni-Travelling Carrier Photo Diode (UTC-PD).

This paper is organized as follows: Design of high gain, high efficiency circular DRA patch antenna using Si-based technology platform where all components are fabricated using microfabrication technique at the same time is illustrated in Section 2. Equations of the novel transformation technique are introduced in Section 3. The proposed systematic circular antenna design procedure is applied to implement four antennas whose desired specifications and the obtained results are analyzed in Section 4 . The conclusions and comparison with others methods are given in Section 5 .

\section{Design of a Circular Patch Reference Antenna}

\subsection{Antenna Geometry and Design}

A reference antenna will be designed according to the design rules to radiate at a certain desired frequency in the MMW range. One of the designs [11] already implemented is an integrated Dielectric Resonator Antenna (DRA) on a Si-based technology platform is designed to operate at $77 \mathrm{GHz}$ millimeter wave applications. The DRA is excited using coplanar waveguide feed (CPW). This design declaims the performance of high gain on-chip DRA on low conductive silicon (conductivity $0.01 \mathrm{~S} / \mathrm{m}$ ). The proposed DRA antenna element has a $2 \mathrm{GHz}$ bandwidth and a $4.78 \mathrm{~dB}$ gain with $98 \%$ radiation efficiency. This antenna witnesses a great enhancement in performance by comparing it with previously reported antennas [12], [13], [14], [15] and [16]. 
The designed circular antenna is shown in Figure 1. A co-planar strip line of signal width, $\mathrm{S}=$ $0.2 \mathrm{~mm}$, length, $\mathrm{S}_{1}=1 \mathrm{~mm}, \mathrm{~g}_{1}=0.7 \mathrm{~mm}$ and gap width $\mathrm{g}=0.1206 \mathrm{~mm}$, is etched on the gold coated ground plane of length $\mathrm{x}$ width, $\mathrm{L} \times \mathrm{W}=1.5 \times 1.5 \mathrm{~mm}$, and thickness $\mathrm{t}_{\mathrm{g}}=0.002 \mathrm{~mm}$, is shown in Figure 1(a) and (b). A low conductive silicon (conductivity $=0.01 \mathrm{~s} / \mathrm{m}$ ) DR material was used as the radiating element. The dimensions of the Circular DRA: $d_{1}=0.4 \mathrm{~mm}$ and $\mathrm{d}_{\mathrm{DRA}}=1.2 \mathrm{~mm}$; is as shown in Figure 1 and summarized in Table 1.
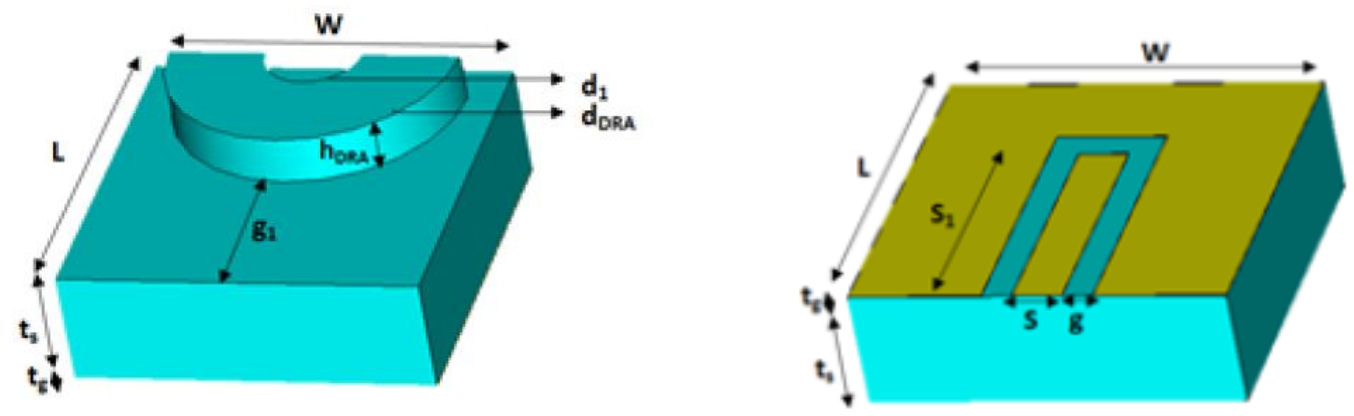

Fig. 1. (a) Circular geometry of the designed DRA; (b) CPW feed of the designed DRA.

Table 1. Dimensions of the designed circular antenna

\begin{tabular}{c|c|c|c|c|c|c|c|c|c|c|c}
\hline \hline Dimension & $\mathrm{L}$ & $\mathrm{W}$ & $\mathrm{t}_{\mathrm{s}}$ & $\mathrm{t}_{\mathrm{g}}$ & $\mathrm{g}_{1}$ & $\mathrm{~g}$ & $\mathrm{~S}$ & $\mathrm{~S}_{1}$ & $\mathrm{~d}_{1}$ & $\mathrm{~d}_{\mathrm{DRA}}$ & $\mathrm{H}_{\text {DRA }}$ \\
\hline Value $(\mathbf{m m})$ & 1.5 & 1.5 & 0.475 & 0.002 & 0.7 & 0.1206 & 0.2 & 1 & 0.4 & 1.2 & 0.2 \\
\hline \hline
\end{tabular}

\subsection{Circular Antenna Simulation}

Using a simulation tool, in this case IE3D, it is shown from Figure 2 that the simulated return loss, $S_{11}$ indicates that this antenna radiates at a frequency of $76.998 \mathrm{GHz}$ and $\mathrm{S}_{11}$ of -21.7227 $\mathrm{dB}$. So, no need for optimization. Using IE3D simulation tool, Figure 2 shows the resulting $\mathrm{S}_{11}$. The antenna now radiates at 76.998 with $-21.7227 \mathrm{~dB}$ and a band width of $15.7992 \mathrm{GHz}$ and antenna efficiency of $98.539 \%$. The other designed antenna parameters such as: Band Width, BW, efficiency, $e_{o}$ is shown in Figure 3 and gain, $G$ is shown in Figure 4.

Efficiency Vs. Frequency

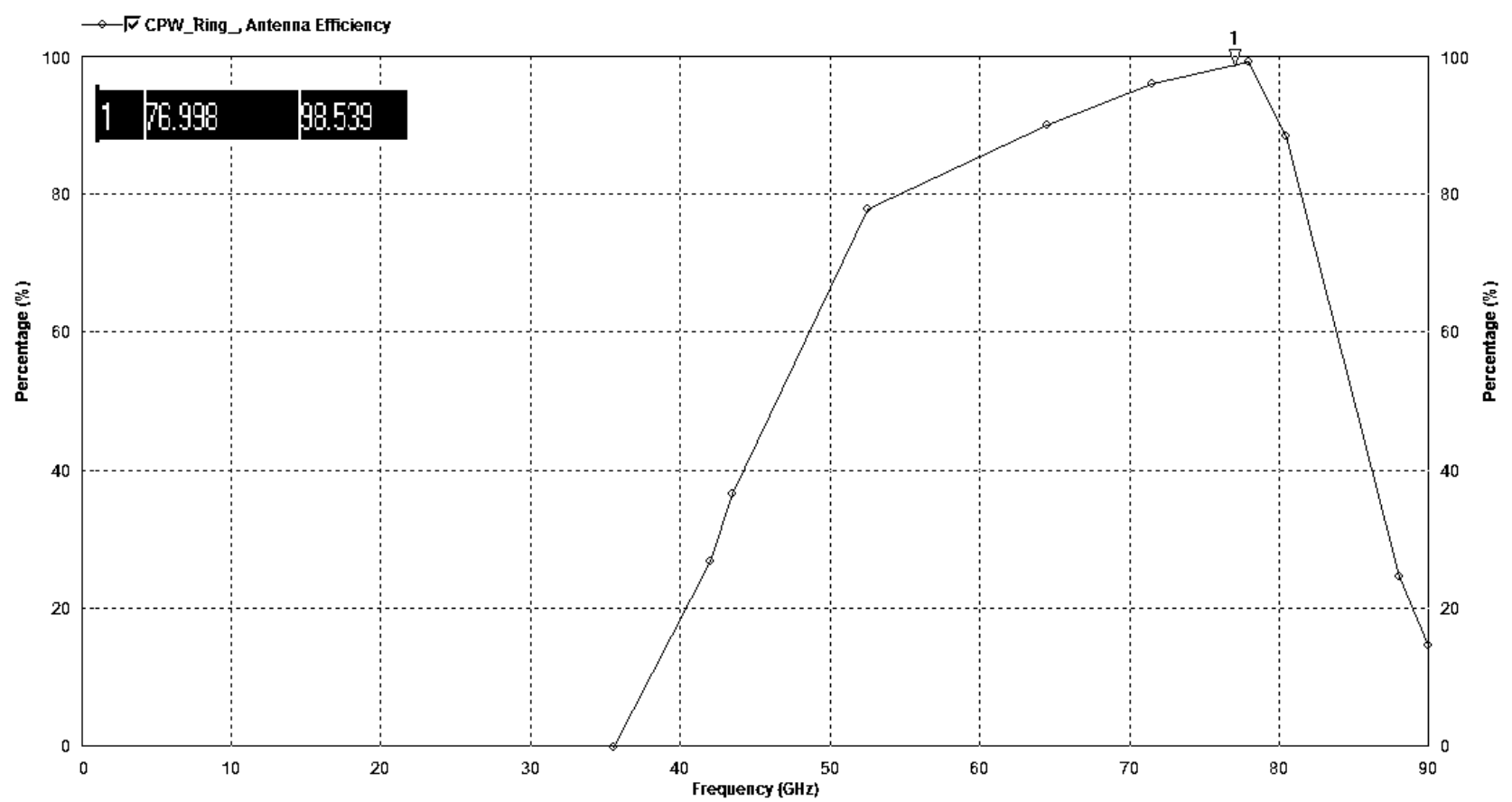

Fig. 2. Circular CPW Feeding Simulated Antenna Efficiency of the Optimized Antenna $3 / 12$ 


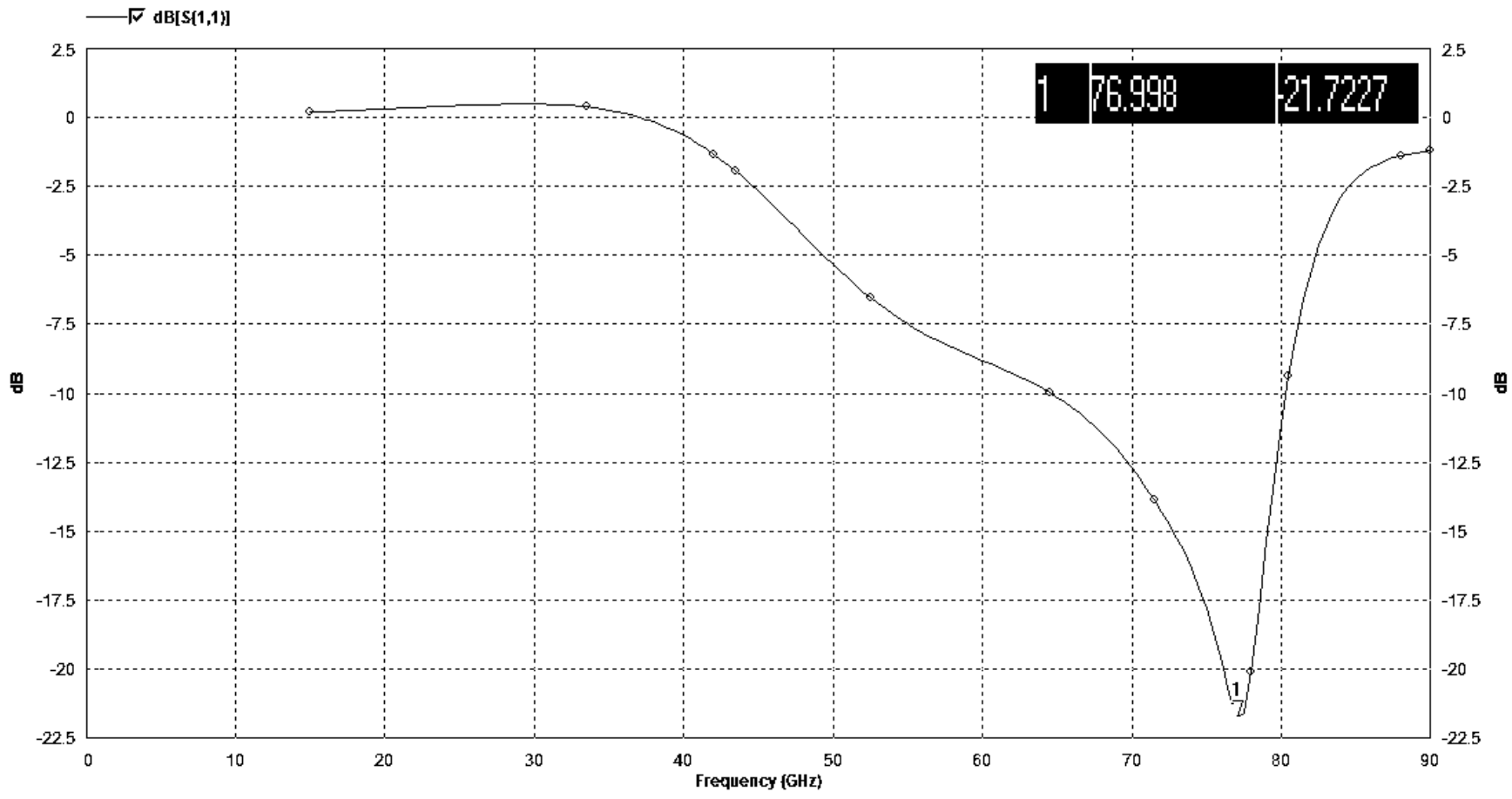

Fig. 3. Circular CPW Feeding Simulated Return Losses $\left(\mathrm{S}_{11}\right)$ of the Designed Antenna.

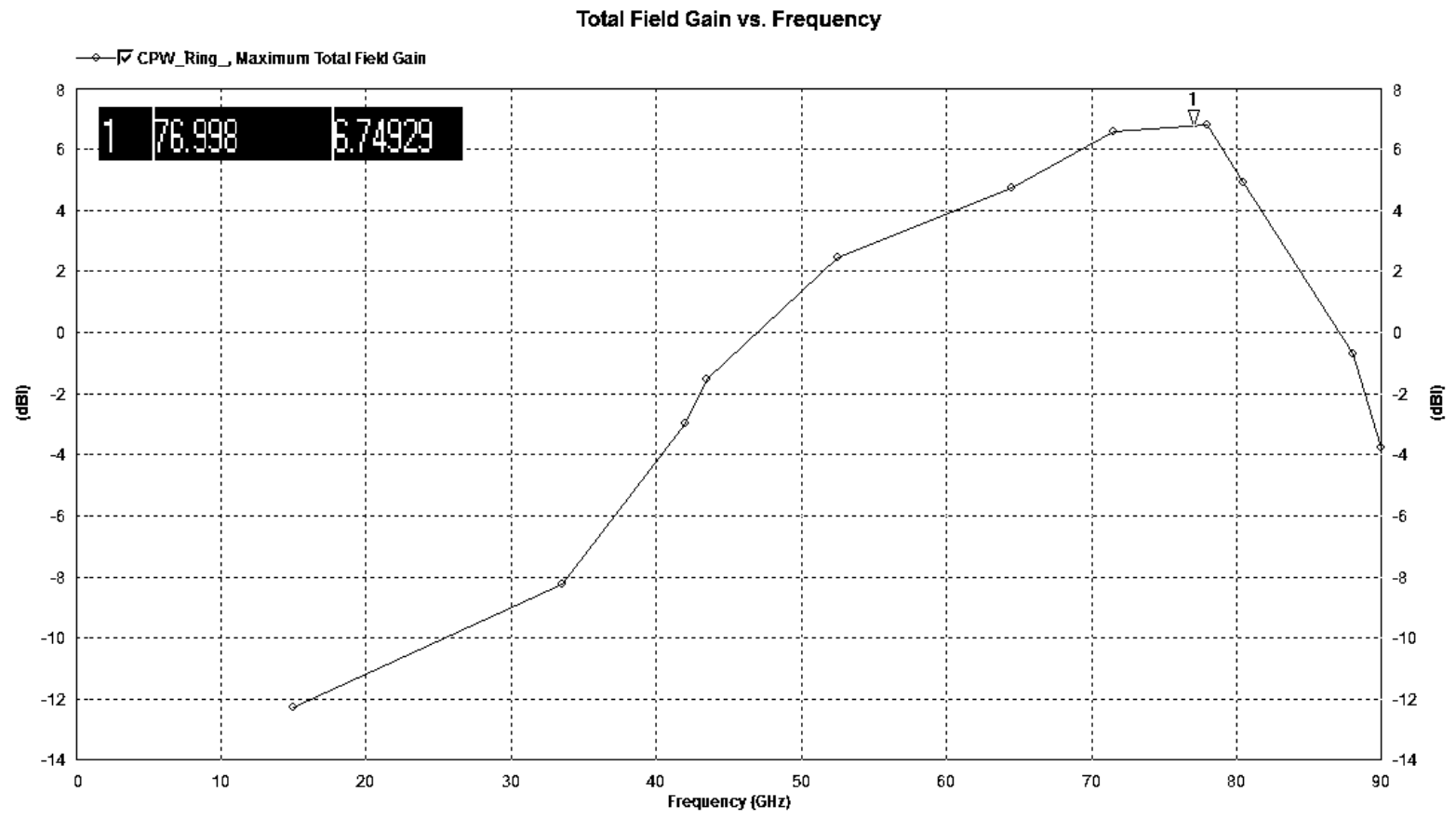

Fig. 4. Circular CPW feeding simulated gain, $\mathrm{G}$ of the optimized antenna

\section{Generic Transformation for Single Band Antenna}

Section 2 illustrates an optimized MMW single band antenna designed based on Dielectric Resonator Antenna (DRA) in a Si-based technology platform for $77 \mathrm{GHz}$ MMW applications. The obtained results shown in Figure 3 to Figure 5 and Table 2 to Table 3 satisfy the desired antenna design specification. Therefore, we will take this design as reference and then derive generic transformation equations to be utilized to design any single band antenna with arbitrary specifications. 
To design an antenna working on a certain frequency (single band), we first need to make some analytical calculations, use a simulation tool to get results then make several optimizations processes for more accurate results which in most of the cases it is considered to be a very exhausting process with no confirmation of reaching an excellent design.

However, there must be easier steps to design an antenna, going through all the designing steps will be time consuming, unless there is a method to get the new design based on a previously designed one, without the need for complex calculations and without the need for analytical analysis and initial design steps.

It is well known that the frequency is inversely proportional to the length; means to increase frequency, the lengths of the parameters must be decreased and vice versa; this information will be considered in designing new antennas based on a reference one.

Define a ratio; $R_{\text {ref }}$ represents the ratio between resonance frequencies: designed frequency, $f_{\text {designed }}$ and desired frequency, $f_{\text {desired }}$ as:

$R_{\text {ref }}=\frac{f_{\text {designed }}}{f_{\text {desired }}}$

Equation (1) represents the frequency transformation. This ratio will be considered as a reference to normalize the corresponding ratios when designing any other desired antenna as will be illustrated in the following section.

The idea is to get a previously designed antenna, optimize it as much as possible to use it as a reference antenna then using it to build a new design by multiplying the old dimension lengths with this ratio, $R_{r e f}$. The resulting dimensions will lead to the new antenna design.

$L_{\text {desired }}=L_{\text {designed }} x R_{\text {ref }}$

Equation (2) represents the Frequency Transformation Equation.

Finally, do only one optimization step by using the same ratio but with the obtained dimension, and then new antenna for the desired operating frequency is obtained without wasting time in designing it from scratch.

$$
L_{\text {optimized }}=L_{\text {designed }} x R_{\text {ref }}
$$

Equation (3) represents the Optimization Equation.

The following section illustrates the utilization of the frequency transformation and optimization equations: (1), (2) and (3) of the reference antenna that radiates at $77 \mathrm{GHz}$ to 35 , 60, 94 and $120 \mathrm{GHz}$ antennas.

\section{Applications}

\subsection{Design of a Circular MMW Antenna with Operating Frequency $35 \mathrm{GHz}$}

To design the antenna geometry to have radiating frequency of $35 \mathrm{GHz}$, first apply Equation (2) to obtain the values of the dimensions of the desired design as follows.

$L_{35}=L_{76.998} \times \frac{76.998}{35}$ 
As a result, the dimensions of the desired antenna are listed in Table 2.

The obtained $S_{11}$ curve after simulation is shown in Figure 5. The antenna radiates at $35.502 \mathrm{GHz}$ with $-16.8013 \mathrm{~dB}$, bandwidth of $3.22746 \mathrm{GHz}$; these results need optimization.

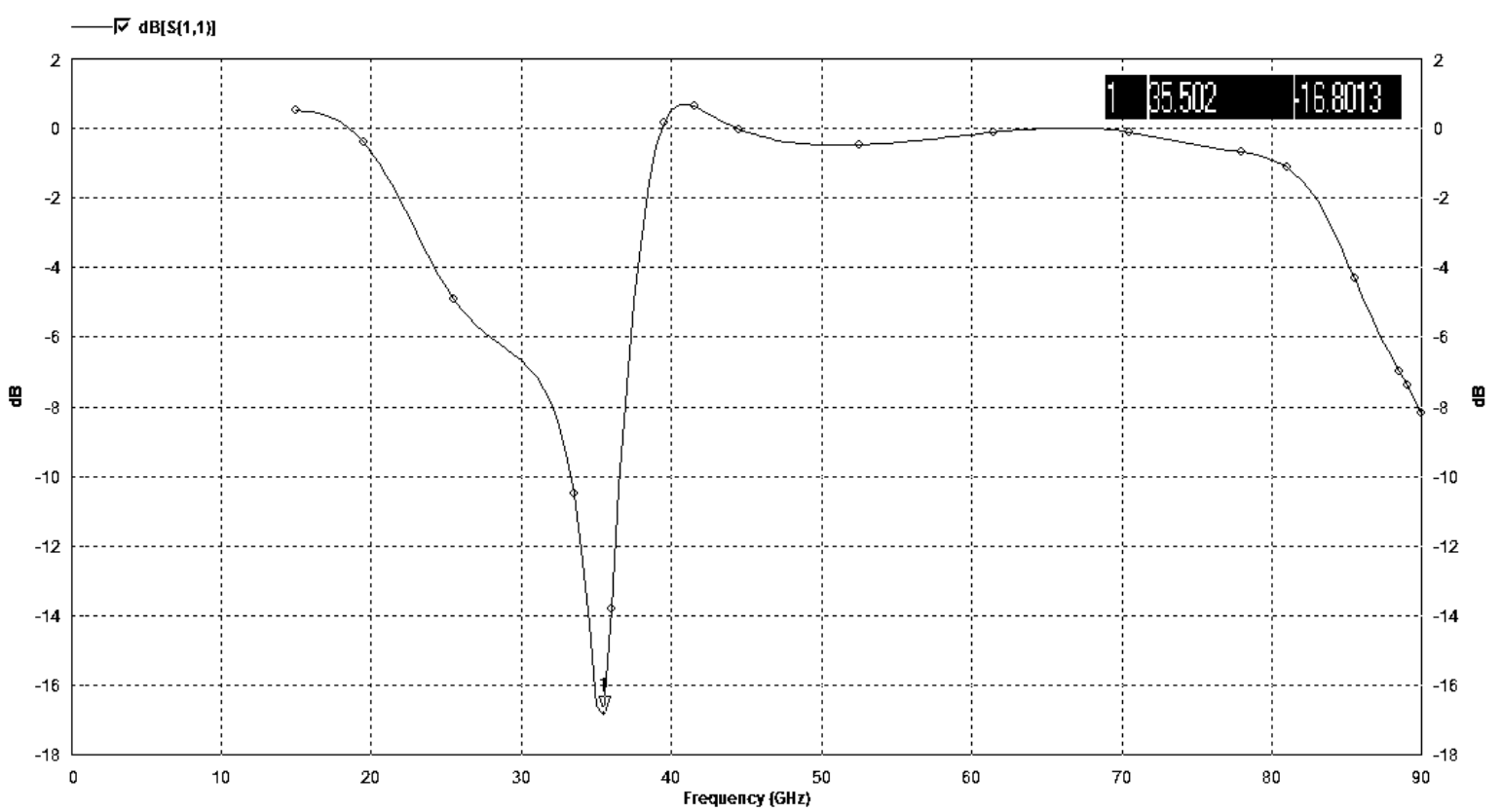

Fig. 5. $\mathrm{S}_{11}$ Curve for the designed circular antenna at operating frequency $35 \mathrm{GHz}$

Table 2. Dimensions of the desired circular antenna working at $35 \mathrm{GHz}$

\begin{tabular}{l|l|l|l|l|l|l|l|l|l|l|l}
\hline \hline Dimension & $\mathrm{L}$ & $\mathrm{W}$ & $\mathrm{t}_{\mathrm{s}}$ & $\mathrm{t}_{\mathrm{g}}$ & $\mathrm{g}_{1}$ & $\mathrm{~g}$ & $\mathrm{~S}$ & $\mathrm{~S}_{1}$ & $\mathrm{~d}_{1}$ & $\mathrm{~d}_{\text {DRA }}$ & $\mathrm{H}_{\text {DRA }}$ \\
\hline Value (mm) & 3.3 & 3.3 & 1.045 & 0.0044 & 1.54 & 0.2653 & 2.2 & 0.44 & 0.0 .88 & 2.6399 & 0.44 \\
\hline \hline
\end{tabular}

For optimization, Equation (3) is used and the result is shown in Table 3.

$L_{35}=L_{35.502} \times \frac{35.502}{35}$

Table 3. Dimensions of the optimized circular antenna working at $35 \mathrm{GHz}$

\begin{tabular}{c|c|c|c|c|c|c|c|c|c|c|c}
\hline \hline Dimension & $\mathrm{L}$ & $\mathrm{W}$ & $\mathrm{t}_{\mathrm{s}}$ & $\mathrm{t}_{\mathrm{g}}$ & $\mathrm{g}_{1}$ & $\mathrm{~g}$ & $\mathrm{~S}$ & $\mathrm{~S}_{1}$ & $\mathrm{~d}_{1}$ & $\mathrm{~d}_{\text {DRA }}$ & $\mathrm{H}_{\text {DRA }}$ \\
\hline Value (mm) & 3.3474 & 3.3474 & 1.06004 & 0.00446 & 1.562 & 0.2691 & 0.4464 & 2.2316 & 0.8926 & 2.6778 & 0.4463 \\
\hline \hline
\end{tabular}

Summary of the antenna parameters are listed in Table 4 and the performance parameters are shown in Figure 6.

Table 4. Parameters of the optimized circular antenna working at $35 \mathrm{GHz}$.

\begin{tabular}{l|l|l|l|l}
\hline \hline Parameter & Operating Frequency, f & Band Width, BW & Gain, G & Efficiency, $\mathrm{e}_{\mathrm{o}}$ \\
\hline Value & $35 \mathrm{GHz}$ & $3.22746 \mathrm{GHz}$ & $6.88587 \mathrm{dBi}$ & $97.8769 \%$ \\
\hline \hline
\end{tabular}

To reach a result near this with the conventional design rules, many steps will be considered in designing then more steps will be considered in optimizing the result to reach the desired radiating frequency. 


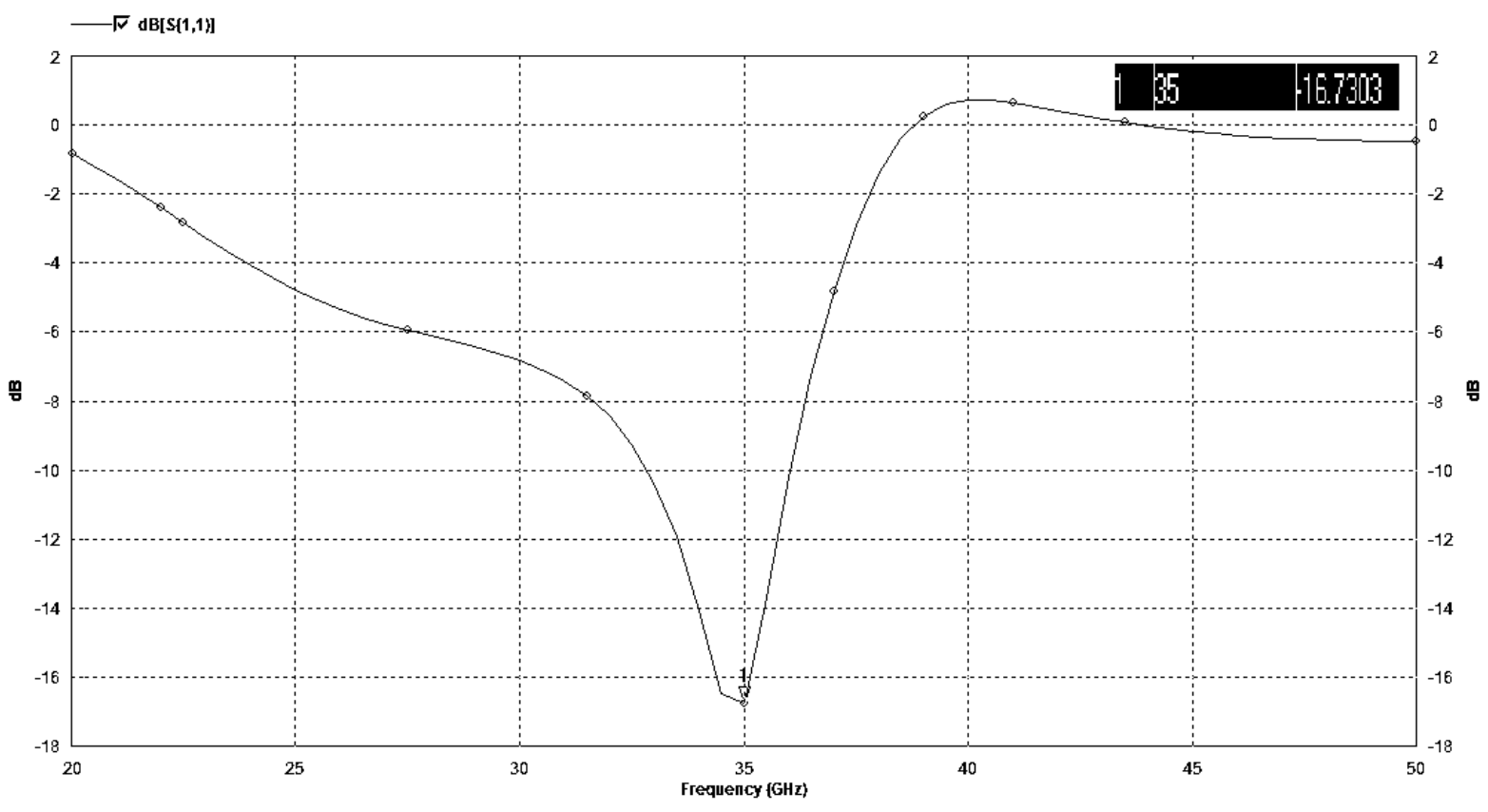

Fig. 6. $\mathrm{S}_{11}$ Curve for the optimized circular antenna at operating frequency $35 \mathrm{GHz}$

\subsection{Design of a Circular MMW Antenna with Operating Frequency $60 \mathrm{GHz}$}

Now, we would like to transfer the radiating frequency from 77 to $60 \mathrm{GHz}$. Instead of going through all the design methods; analytical design, initial design using simulation tool and finally, performing several optimization steps to obtain the desired radiating frequency, we can simply use a very simple ratio based on the results obtained from the reference antenna to reach the desired frequency.

The idea is simple. Since we simulated the reference antenna to find the exact radiating frequency, which is $77.0041 \mathrm{GHz}$ (not $77 \mathrm{GHz}$, precision is very important to obtain good results without wasting time in optimization steps) and the desired new frequency is $60 \mathrm{GHz}$, doing the calculations in Equation (2) to reach the new design with the required frequency.

$L_{60}=\frac{76.998}{60} \times L_{76.998}$

The geometry is the same as the reference antenna except for the scale; the dimensions of the new antenna are listed in Table 5

Table 5. Dimensions of the desired circular antenna working at $60 \mathrm{GHz}$

\begin{tabular}{l|l|l|l|l|l|l|l|l|l|l|l}
\hline \hline Dimension & $\mathrm{L}$ & $\mathrm{W}$ & $\mathrm{t}_{\mathrm{s}}$ & $\mathrm{t}_{\mathrm{g}}$ & $\mathrm{g}_{1}$ & $\mathrm{~g}$ & $\mathrm{~S}$ & $\mathrm{~S}_{1}$ & $\mathrm{~d}_{1}$ & $\mathrm{~d}_{\mathrm{DRA}}$ & $\mathrm{H}_{\mathrm{DRA}}$ \\
\hline Value (mm) & 1.925 & 1.925 & 0.6095 & 0.00257 & 0.8983 & 0.1548 & 0.2566 & 1.2833 & 0.5134 & 1.54 & 0.2567 \\
\hline \hline
\end{tabular}

The $\mathrm{S}_{11}$ curve is shown in Figure 7 using IE3D simulation tool, it is very important to increase the lengths with the same ratio and to maintain the shape of the antenna.

As the lengths increase, the radiating frequency will decrease; we consider radiation of a certain frequency if the $S_{11}$ value is $-10 \mathrm{~dB}$ or less. 
The radiating frequency for Figure 7 is at $60 \mathrm{GHz}$ and a bandwidth of $6.19598 \mathrm{GHz}$. So, this result was very satisfying and now we have an antenna designed at $60 \mathrm{GHz}$ with minimum effort and time consumption which is ready to be used in many applications as described before. Summary of the parameters are listed in Table 6.

Table 6. Parameters of the optimized circular antenna working at $60 \mathrm{GHz}$

\begin{tabular}{l|l|l|l|l}
\hline \hline Parameter & Operating Frequency, $\mathrm{f}$ & Band Width, BW & Gain, G & Efficiency, $\mathrm{e}_{\mathrm{o}}$ \\
\hline Value & $60 \mathrm{GHz}$ & $6.19598 \mathrm{GHz}$ & $7.10103 \mathrm{dBi}$ & $98.4166 \%$ \\
\hline \hline
\end{tabular}

\subsection{Design of a Circular MMW Antenna with Operating Frequency $94 \mathrm{GHz}$}

To transfer the radiating frequency of the antenna to $94 \mathrm{GHz}$, a similar approach of that of 35 and $60 \mathrm{GHz}$ will be considered, using Equation (2) to transfer the frequency.

$L_{94}=\frac{76.998}{94} \times L_{76.998}$

As a result, all the lengths of the derived antenna will be smaller than that of the reference one; this is because the frequency is inversely proportional to the length. After calculation, the dimensions of the new antenna are listed in Table 7.

Table 7. Dimensions of the Desired Circular Antenna Working at $94 \mathrm{GHz}$

\begin{tabular}{c|c|c|c|c|c|c|c|c|c|c|c}
\hline \hline Dimension & $\mathrm{L}$ & $\mathrm{W}$ & $\mathrm{t}_{\mathrm{s}}$ & $\mathrm{t}_{\mathrm{g}}$ & $\mathrm{g}_{1}$ & $\mathrm{~g}$ & $\mathrm{~S}$ & $\mathrm{~S}_{1}$ & $\mathrm{~d}_{1}$ & $\mathrm{~d}_{\text {DRA }}$ & $\mathrm{H}_{\text {DRA }}$ \\
\hline Value (mm) & 1.2286 & 1.2286 & 0.38906 & 0.00164 & 0.5734 & 0.0988 & 0.1638 & 0.8191 & 0.3276 & 0.983 & 0.1638 \\
\hline \hline
\end{tabular}

Using IE3D tool to obtain the result of $\mathrm{S}_{11}$ shown in Figure 8, the resulted radiating frequency is at $93.5656 \mathrm{GHz}$ with bandwidth of $20.3279 \mathrm{GHz}$, close to $94 \mathrm{GHz}$, but further optimization (only one step) can be done to reach a more precise value approximately equals to $94 \mathrm{GHz}$.

To reach a more precise and very close design to $94 \mathrm{GHz}$, the same idea is used by multiplying the lengths by a factor of Equation (1). From Equation (3) we get:

$L_{94}=\frac{93.5656}{94} \times L_{93.5656}$

The new and optimized antenna parameters are calculated and listed in Table 8 .

Table 8. Dimensions of the optimized circular antenna working at $94 \mathrm{GHz}$

\begin{tabular}{c|c|c|c|c|c|c|c|c|c|c|c}
\hline \hline Dimension & $\mathrm{L}$ & $\mathrm{W}$ & $\mathrm{t}_{\mathrm{s}}$ & $\mathrm{t}_{\mathrm{g}}$ & $\mathrm{g}_{1}$ & $\mathrm{G}$ & $\mathrm{S}$ & $\mathrm{S}_{1}$ & $\mathrm{~d}_{1}$ & $\mathrm{~d}_{\mathrm{DRA}}$ & $\mathrm{H}_{\text {DRA }}$ \\
\hline Value & 1.223 & 1.223 & 0.163 & 0.00163 & 0.5709 & 0.0984 & 0.163 & 0.8154 & 0.326 & 0.9784 & 0.123 \\
\hline \hline
\end{tabular}

The $S_{11}$ curve obtained using IE3D simulation tool is as shown in Figure 9, after using only one optimization step, the new antenna design radiates at $94.0164 \mathrm{GHz}$ and $20.3279 \mathrm{GHz}$ bandwidth. Table 9 summarizes the antenna parameters.

Now we have an antenna design that radiates at $94 \mathrm{GHz}$ with negligible error.

Table 9. Parameters of the optimized circular antenna working at $94 \mathrm{GHz}$

\begin{tabular}{l|l|l|l|l}
\hline \hline Parameter & Operating Frequency, f & Band Width, BW & Gain, G & Efficiency, $\mathrm{e}_{\mathrm{o}}$ \\
\hline Value & $94.0164 \mathrm{~Hz}$ & $20.3279 \mathrm{GHz}$ & $6.87148 \mathrm{dBi}$ & $98.1149 \%$ \\
\hline \hline
\end{tabular}




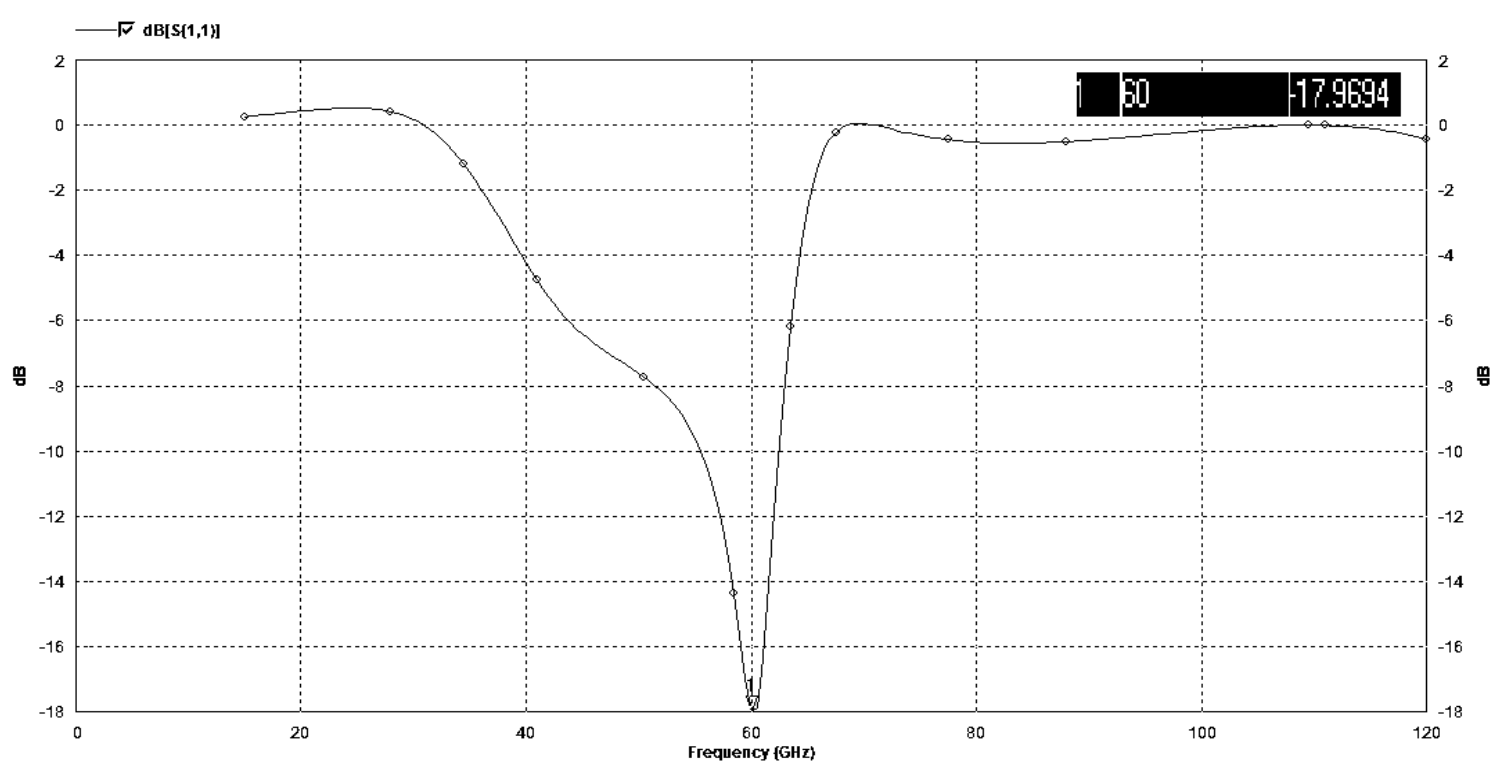

Fig. 7. $S_{11}$ Curve for the designed circular antenna at operating frequency $60 \mathrm{GHz}$

\subsection{Design of a MMW Antenna with Operating Frequency $120 \mathrm{GHz}$}

Now we need to transfer the radiating frequency from $77 \mathrm{GHz}$ to $120 \mathrm{GHz}$, the use of $120 \mathrm{GHz}$ is very important in several applications mentioned in a previous section.

To transfer frequency, the design Equation (2) is used with the same idea as before.

$L_{120}=\frac{77.998}{120} \times L_{77.998}$

With the same geometry except for antenna size, the new dimensions are listed in Table 10.

Table 10. Dimensions of the desired circular antenna working at $120 \mathrm{GHz}$

\begin{tabular}{c|c|c|c|c|c|c|c|c|c|c|c}
\hline \hline Dimension & $\mathrm{L}$ & $\mathrm{W}$ & $\mathrm{t}_{\mathrm{s}}$ & $\mathrm{t}_{\mathrm{g}}$ & $\mathrm{g}_{1}$ & $\mathrm{~g}$ & $\mathrm{~S}$ & $\mathrm{~S}_{1}$ & $\mathrm{~d}_{1}$ & $\mathrm{~d}_{\text {DRA }}$ & $\mathrm{H}_{\text {DRA }}$ \\
\hline Value (mm) & 0.9624 & 0.9624 & 0.30482 & 0.00128 & 0.4492 & 0.0773 & 0.1284 & 0.6416 & 0.2566 & 0.77 & 0.1283 \\
\hline \hline
\end{tabular}

The $\mathrm{S}_{11}$ curve is shown in Figure 10 using IE3D simulation tool, it is very important to decrease the lengths with the same ratio and to maintain the shape of the antenna, as the lengths decreases, the radiating frequency will increase.

The radiating frequency is at 118.525 ; we can either accept this result as it is near to $120 \mathrm{GHz}$ or we can make optimization once.

We can use the simple ratio in Equation (1) to make optimization, instead of 77.998 , we can write 118.525 using Equation (3).

$$
L_{120}=\frac{118.525}{120} \times L_{118.525}
$$

The dimensions of the optimized antenna are listed in Table 11. 


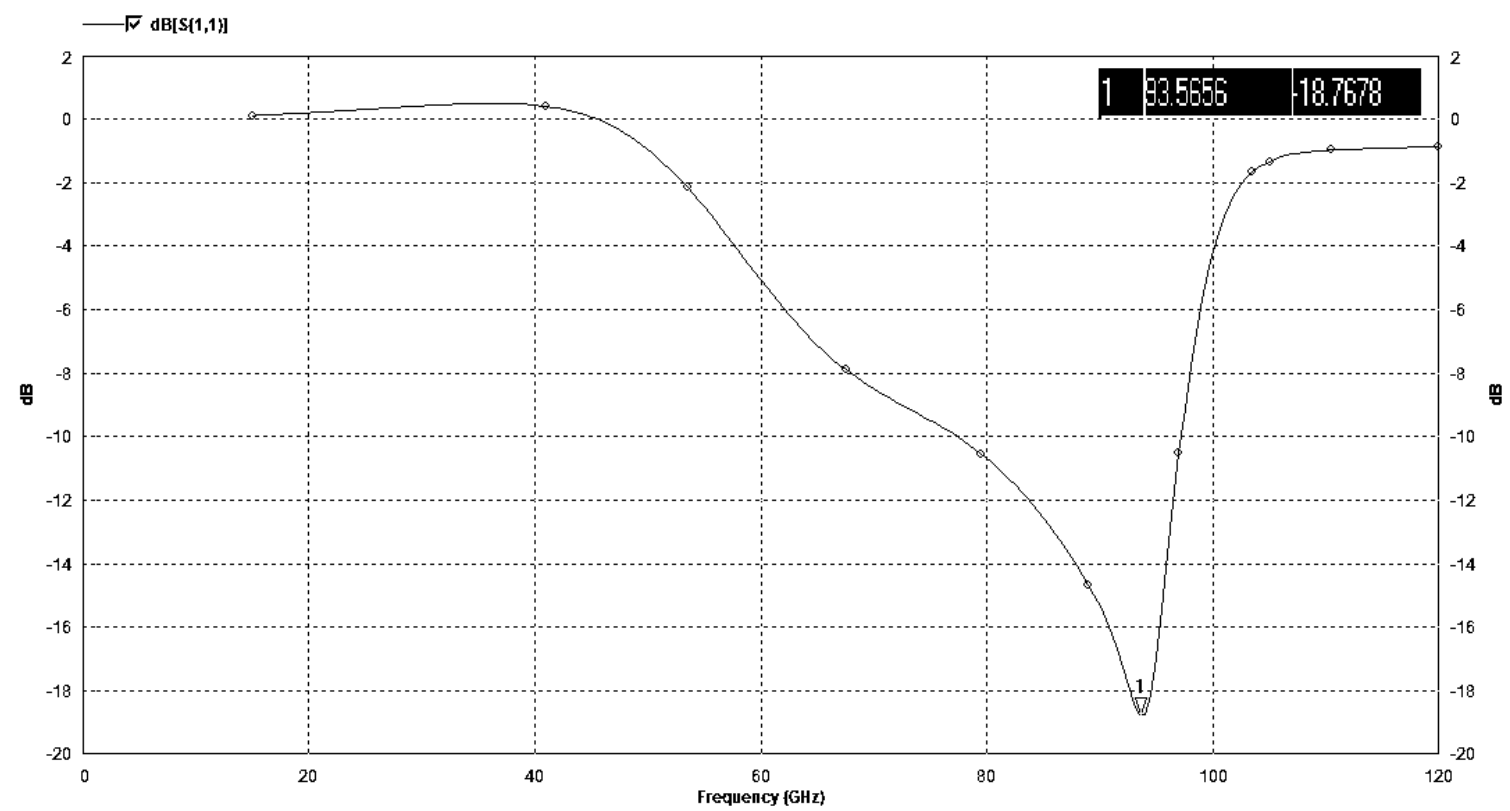

Fig. 8. $\mathrm{S}_{11}$ Curve for the designed circular antenna at operating frequency $94 \mathrm{GHz}$

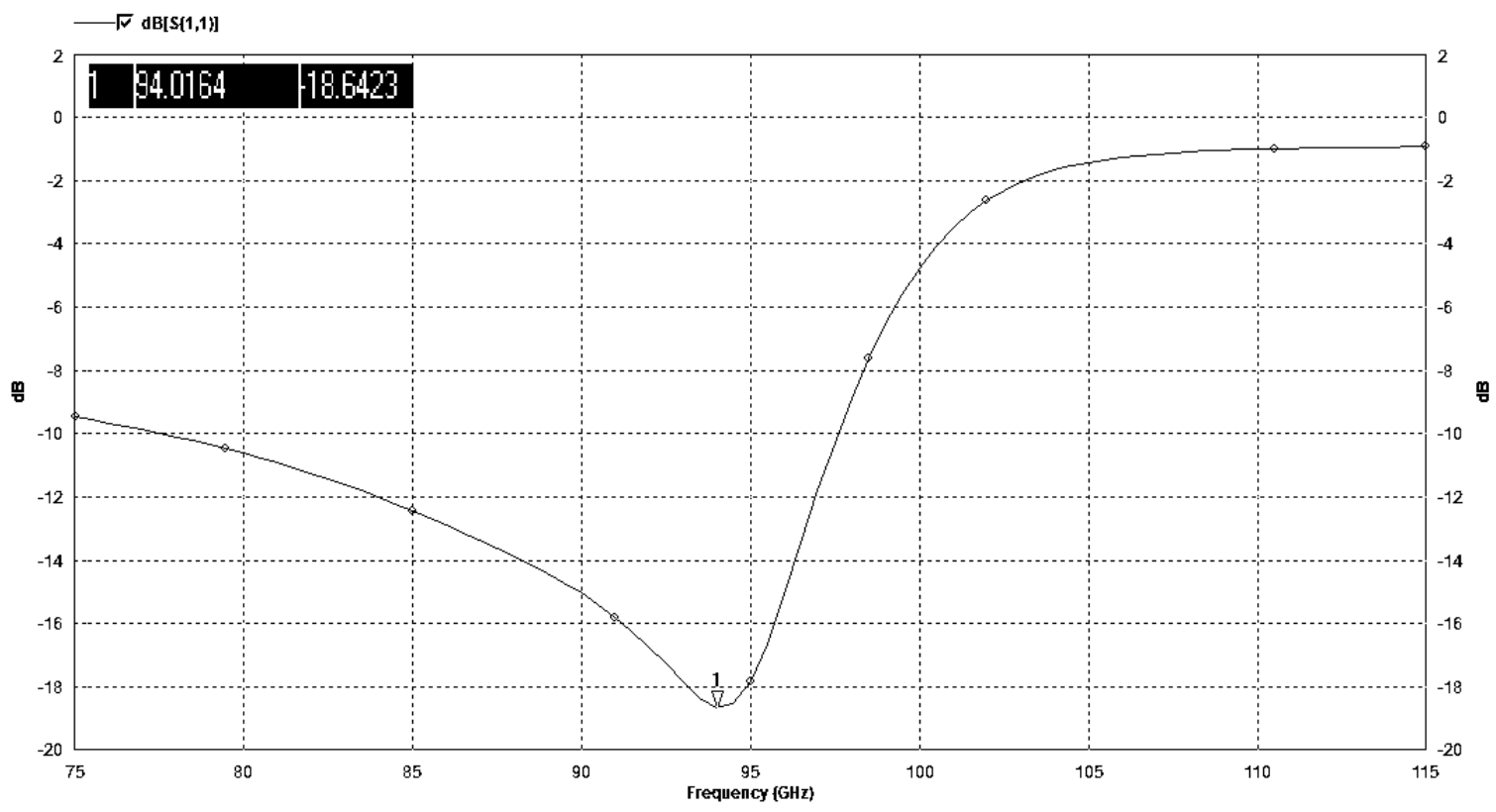

Fig. 9. $\mathrm{S}_{11}$ Curve for the optimized circular antenna at operating frequency $94 \mathrm{GHz}$

Table 11. Dimensions of the optimized circular antenna working at $120 \mathrm{GHz}$

\begin{tabular}{l|l|l|l|l|l|l|l|l|l|l|l}
\hline \hline Dimension & $\mathrm{L}$ & $\mathrm{W}$ & $\mathrm{t}_{\mathrm{s}}$ & $\mathrm{t}_{\mathrm{g}}$ & $\mathrm{g}_{1}$ & $\mathrm{~g}$ & $\mathrm{~S}$ & $\mathrm{~S}_{1}$ & $\mathrm{~d}_{1}$ & $\mathrm{~d}_{\text {DRA }}$ & $\mathrm{H}_{\text {DRA }}$ \\
\hline
\end{tabular}
\begin{tabular}{l|l|l|l|l|l|l|l|l|l|l|l|l|l}
\hline Value (mm) & 0.9505 & 0.9506 & 0.30104 & 0.00126 & 0.4437 & 0.0764 & 0.1268 & 0.6337 & 0.2534 & 0.7606 & 0.1268 \\
\hline \hline
\end{tabular}

The lengths of the parameters after optimization were smaller than that before optimization, this means the results were predicted, after optimization the radiating frequency is at 120.015 $\mathrm{GHz}$ as shown in Figure 11 with frequency error $0.0125 \%$ which is approximately $120 \mathrm{GHz}$ and $29.9795 \mathrm{GHz}$ bandwidth. So, these results were very satisfying. The summary of the parameters is listed in Table 12. 


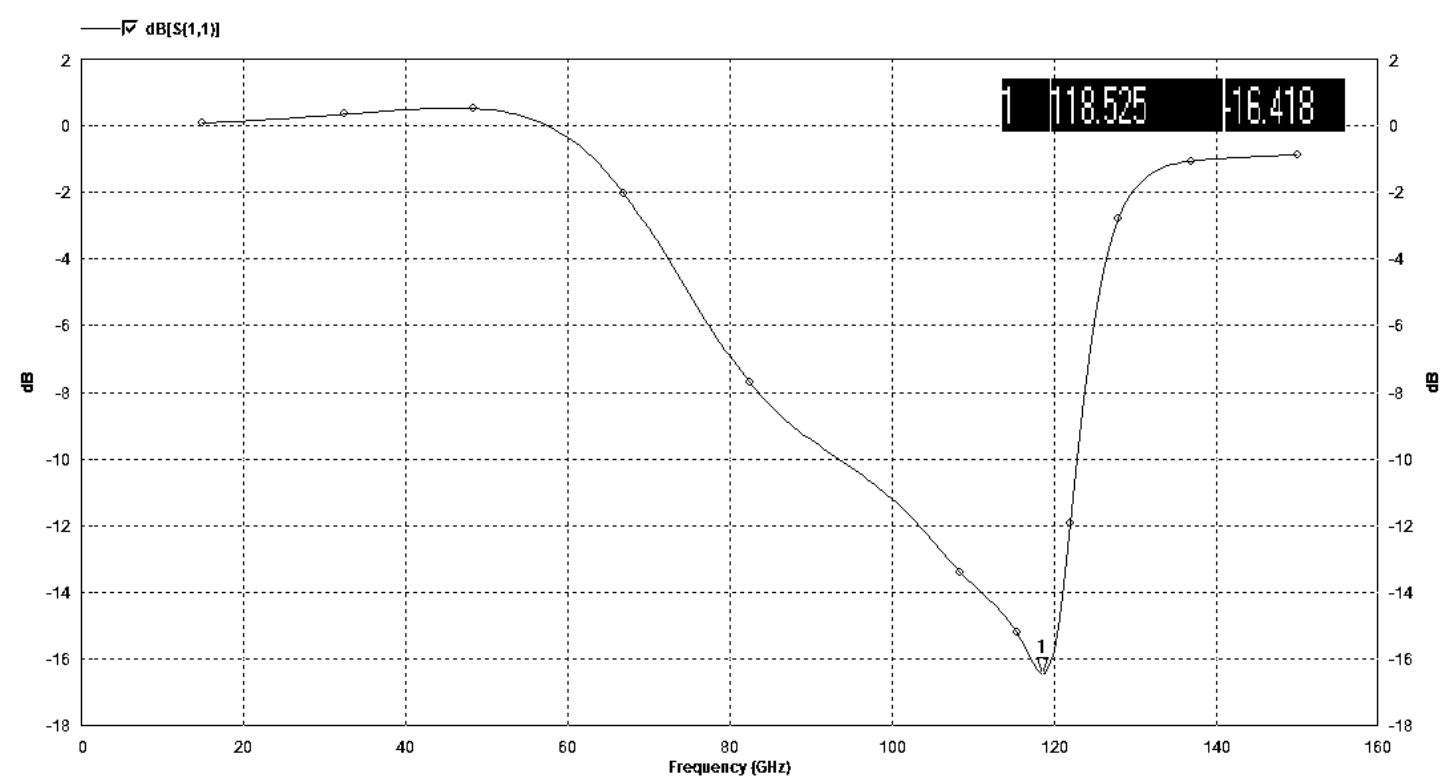

Fig. 10. $\mathrm{S}_{11}$ Curve for the designed circular antenna at operating $120 \mathrm{GHz}$

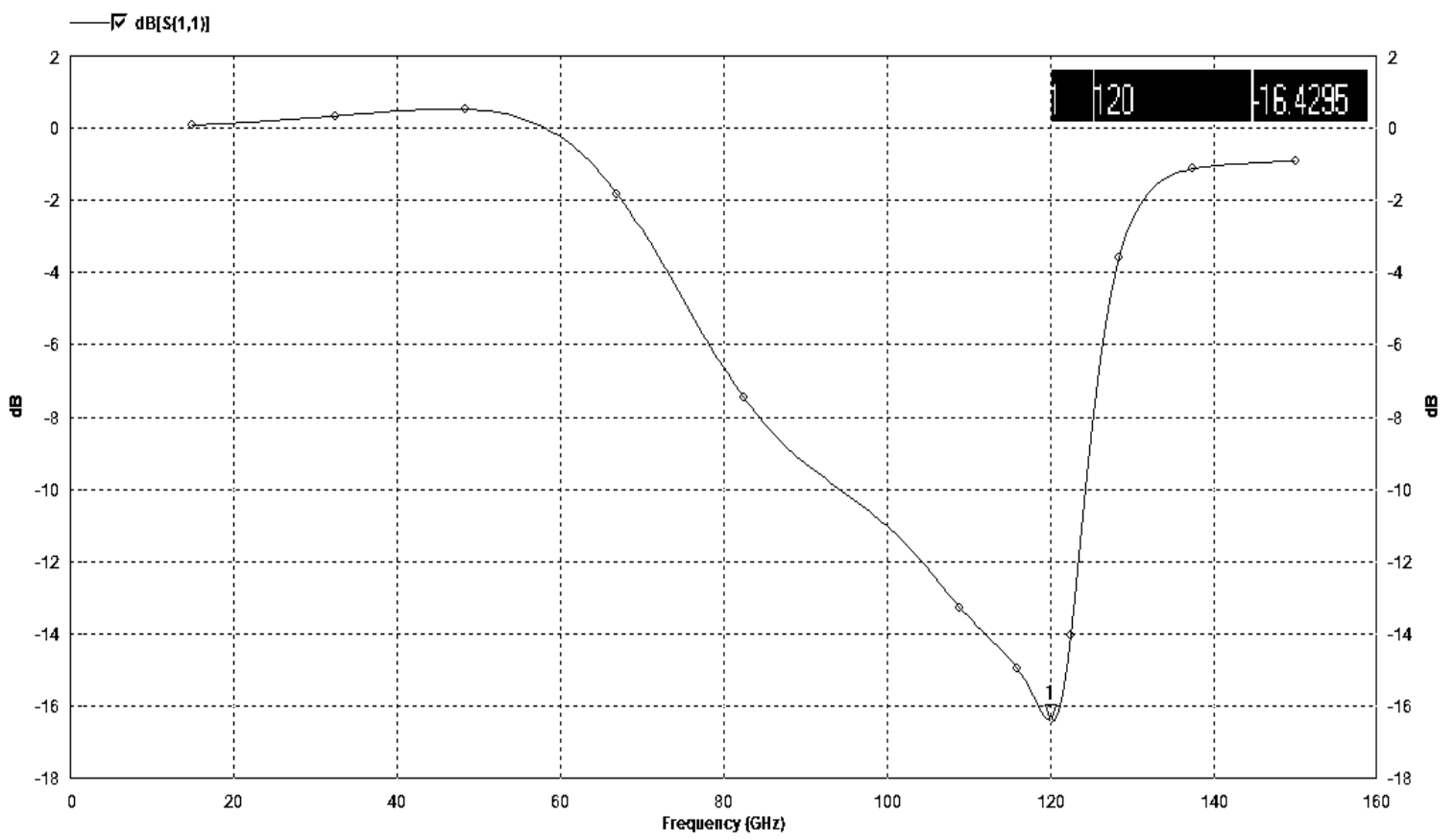

Fig. 11. $\mathrm{S}_{11}$ Curve for the optimized circular antenna at frequency $120 \mathrm{GHz}$

Table 12. Parameters of the optimized circular antenna working at $120 \mathrm{GHz}$

\begin{tabular}{l|l|l|l|l}
\hline \hline Parameter & Operating frequency, f & Band width, BW & Gain, G & Efficiency, $e_{o}$ \\
\hline Value & $120 \mathrm{GHz}$ & $29.9795 \mathrm{GHz}$ & $6.63667 \mathrm{dBi}$ & $96.3396 \%$ \\
\hline \hline
\end{tabular}




\section{Conclusion}

In this paper, a novel transformation technique and design equations are derived to design single band circular antennas for Millimeter Wave (MMW) applications. An integrated Dielectric Resonator Antenna (DRA) in a Si-based technology platform is used to design a reference antenna. Then the derived transformation and design equations are applied to transform this reference antenna to other desired MMW antennas with desired specifications different from the reference one. In order to demonstrate the validity of this approach, four typical examples for MMW antennas that are used in different wireless communication are designed and simulated. The obtained results of these designs indicate that this technique is easy, fast, generic and accurate.

\section{References}

[1] Huang, Kao-Cheng and Zhaocheng Wang, Millimetre Wave Communication System, 2011.

[2] Rappaport T. S., Sun Shu, Mayzus R., Zhao Hang, Azar Y., Wang K., Womg G. N. and Schulz J. K [Millimetre Wave Mobile Communications for 5G Cellular: It Will Work!] ,2013.

[3] eesa2016:Telecommunications \& Integrated Applications, http://m.esa.int/Our_Activities /Telecommunications Integrated Applications/Satellite frequency bands.html.

[4] SIVERSIMA 2016: Radar Sensors, http://siversima.com/products/radar-sensors/.html

[5] Seongwook Lee, Seokhyun Kang, and Seong-Cheol Kim and Jae-Eun Lee. Radar Cross Section Measurement with $77 \mathrm{GHz}$ Automotive FMCW Radar, 2016.

[6] Tim Martin Böbel, Matthias Rabel and Thomas Dallmann, Dirk Heberling. A Frequency Steerable Substrate-Integrated Waveguide Slot Antenna for $77 \mathrm{GHz}$ Radar Application, 2016.

[7] Zhiming Chen, Chun -Cheng Wang and Payam Heydari. A BICMOS W-Band 2x2 FocalPlane Array with On-Chip Antenna. IEEE journal of Solid-State Circuits, 2012.

[8] Infenion 2016: Automotive $77 \mathrm{GHz}$ Radar System, http://www.infineon.com /cms/en/applications/automotive/safety/adas/automotive-radar/\#overview.html.

[9] Leland Gilreath, Vipul Jain and Payam Heydari. Design and Analysis of a W-Band SiGe Direct Detection Based Passive Imager Using a Balanced LNA with an Embedded Dicke Switch. IEEE Journal of Solid State Circuits, 2011.

[10] NTT Technical Review 2016: Overview of Millimeter and Terahertz Wave Application Research, https://www.ntt-review.jp/archive/ntttechnical.php?contents=ntr200903sf1.html.

[11] E. Usama, M. Basha, and H. Ghouz. Compact High Gain High Efficiency Co-Planar SiBased DRA Antenna for Millimeter Wave Application, URSI, 978-1-4799-7817, IEEE, 2015.

[12] P.V. Bijumon, A.P. Freunorfer, M.Sayer and Y.M.M. Antar. High Gain On-Chip Dielectric Resonator Antenna Using Silicon Technology for Millimeter Wave Wireless Links, 2007.

[13] Mehdi Seyyed-Esfahlan, Mehmet Kaynak, and Ibrahim Tekin. A77 GHz On-Chip Dipole Antenna with Etched Silicon Substrate, 2012.

[14] Wanlan Yang, Kaixue Ma, Kiat Seng Yeo and Wei Meng Lim. A 60GHz On-Chip Antenna /in/standard CMOS Silicon Technology, 2012.

[15] P.V. Bijumon, Y.M.M. Antar, A.P. Freunorfer and M.Sayer. Integrated Dielectric Resonator Antennas for System On-Chip Applications, 2006.

[16] Yung-Hsiang Chaung, Han-Lin Yue, Cheng-Ying Hsu and Huey-Ru Chuang. A 77GHz Integrated On-Chip Yagi Antenna with Unbalancedto- Balanced Bandpass Filter Using IPD Technology. Proceedings of the Asia-Pacific Microwave Conference (APMC), pp. 449-452, 2011. 